\title{
Amaurosis fugax associated with congenital vascular defect
}

This article was published in the following Dove Press journal:

International Medical Case Reports Journal

4 July 2016

Number of times this article has been viewed

John W Giltner'

Edward R Thomas ${ }^{2}$

William K Rundell ${ }^{3}$

'Boonshoft School of Medicine, Wright State University, Dayton, $\mathrm{OH}$, USA; ${ }^{2}$ Ohio Eyecare Institute, Premier Health Specialists, Dayton, OH, USA; ${ }^{3}$ Department of Surgery, Miami Valley Hospital, Dayton, OH, USA
Correspondence: John Giltner Boonshoft School of Medicine, Wright State University, 3640 Colonel Glenn Hwy Dayton, OH 45435, USA

$\mathrm{Tel}+\mathrm{I} 3303100742$

Email Giltnerj@gmail.com
Abstract: A 68-year-old female with no significant past medical history presented with loss of vision in the lower half of her left eye that lasted $<5$ minutes. No abnormalities were found on ocular or physical exam. Computed tomography angiography and carotid ultrasound were performed, which confirmed the diagnosis as amaurosis fugax with two abnormalities leading to the transient retinal vessel occlusion. First, it was found that the patient has a congenital vascular anomaly, which consisted most notably of a right-sided aortic arch. This vascular anomaly also consisted of abnormal branching of the left subclavian and common carotid arteries, predisposing the patient to turbulent blood flow and increased risk of the formation of an atherosclerotic plaque at the origin of the common carotid artery. This is an abnormal location for a plaque leading to amaurosis fugax compared to the most common location at the carotid bifurcation. Endarterectomy was not performed because of the difficult location of the plaque and tortuosity of the vessel. Rather, medical intervention with antiplatelet and lipid-lowering therapy was initiated to lower the risk of future retinal or cerebral thromboembolic events.

Keywords: amaurosis fugax, aorta, carotid, congenital, defect

\section{Case presentation}

A 68-year-old, otherwise healthy female presented with a sudden, temporary loss of vision in her left eye, which occurred 1 day prior to the encounter. She stated that it seemed like a black window shade was pulled over the bottom half of her eye. The loss of vision lasted for $\sim 1$ minute, which occurred while she was reading a book using reading glasses. She stated that her vision returned spontaneously after a few minutes. She stated that she had no chest pain or palpitations either during the time of visual loss or in the past. She denied recent illnesses, headache, flashes, and floaters. Review of systems was unremarkable. Her ocular history included an uncomplicated cataract extraction in both eyes 2 years prior and dry eyes. Ethical permission was granted by the Premier Health Network. Written patient consent was received for case report presentation.

\section{Medical history}

The patient had a past medical history of rheumatoid arthritis and migraines without aura. Her systemic medications/supplements include baby aspirin (81 mg daily), artificial tears, glucosamine, and vitamin D. Her family history was significant for multiple malignancies including bowel, breast, and colon cancers, heart disease, hypertension, stroke, glaucoma, and macular degeneration. She had no history of glaucoma, macular degeneration, or any heart problems such as atrial fibrillation. She had never used 
any tobacco products and drank alcohol socially. She was allergic to azithromycin and erythromycin, both of which result in a rash.

\section{Examination}

The patient's blood pressure was $140 / 80 \mathrm{mmHg}$, and her pulse was 80 beats per minute, with a regular rate and rhythm. Ocular examination showed a best-corrected visual acuity of 20/25+2 in her right eye and 20/20 in her left eye. Pupils were equal, round, and reactive without any apparent afferent pupillary defect. Extraocular motility and visual fields were full oculus uetrque.

External examination was unremarkable. Intraocular pressure was $14 \mathrm{mmHg}$ oculus uetrque. Anterior slit-lamp examination revealed dry eyes with meibomian gland dysfuncion oculus uetrque, posterior chamber intraocular lenses that were well placed, and was otherwise insignificant. Fundoscopic examination showed clear vitreous and sharp margins of the optic nerve with a cup-to-disc ratio of 0.2 bilaterally. Examination of the macula, vessels, and periphery was normal, showing no signs of a Hollenhorst plaque, embolus, or occluded vessels. No bruits were heard over the carotid arteries.

\section{Diagnosis and workup}

Based on the patient's clinical history and presenting symptoms, a differential diagnosis was made consisting of amaurosis fugax (AFX), transient ischemic attack (TIA), atrial fibrillation, papilledema, and migraine. The patient did not demonstrate any cardiac abnormalities at the time of the event, examination, or in the past, and so the diagnostic focus was shifted to vascular pathology. Based on the history of monocular vision loss lasting $\sim 1$ minute and not associated with any headache, change in posture, or exertion, and a normal cup-to-disc ratio, AFX as a result of retinal hypoperfusion was determined to be the most likely diagnosis. This diagnosis highly raises the suspicion of an ipsilateral carotid atherosclerotic lesion; therefore, computed tomography (CT) angiography was performed to look for a source of an embolism. The most likely source of an atheroembolism in the case of AFX is the carotid bifurcation; ${ }^{1}$ however, an atheroembolus occasionally arises along the length of the common carotid artery, common carotid origin, aortic arch, or calcific aortic valve. For this reason, CT angiography and three-dimensional reconstructions were performed analyzing the aortic arch, great vessels, cervical vessels, and intracranial vessels.

The findings of the CT angiography (Figure 1) revealed a congenital vasculature anomaly, which was previously undiagnosed. The patient had a right-sided aortic arch.

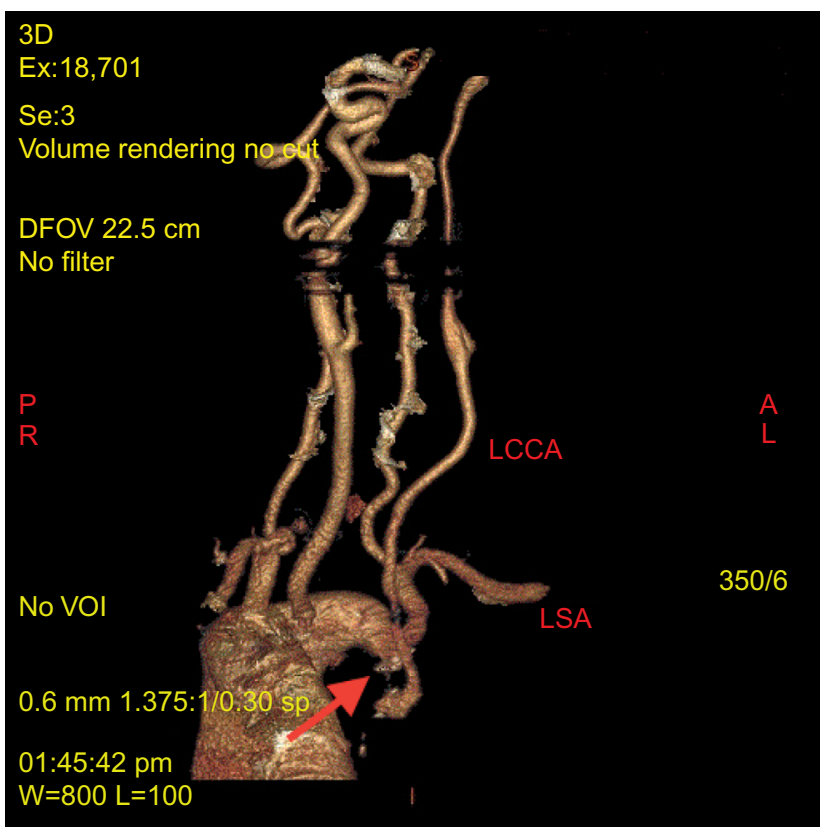

Figure I Patient's aortic arch and neck vessels (computed tomography angiography and $3 \mathrm{D}$ reconstruction).

Note: Arrow indicates the location of atherosclerotic plaque (source of embolization). Abbreviations: 3D, three dimensional; LCCA, left common carotid artery; LSA, left subclavian artery; DFOV, display field of view; VOI, volume of interest.

There was a common origin of the left common carotid and left subclavian arteries that coursed behind the trachea and esophagus. At the origin of the left common carotid artery, there was a $1 \mathrm{~cm}$ unstable plaque that was causing critical, irregular stenosis, resulting in a pinpoint lumen (depicted by arrow in Figure 1). The left carotid system was abnormally small. Vertebral and intracranial arteries were normal with no flow-limiting stenosis. The left common carotid artery also displayed a tortuous route after its origin. After the origin, it coursed caudally then turned $180^{\circ}$ immediately after the stenotic region. Carotid ultrasound was also performed, which confirmed stenosis at the origin of left common carotid artery.

After discovery of the atherosclerotic plaque, a lipid panel was performed, which showed a mixed hyperlipidemia with elevated low-density lipoproteins and triglycerides. A platelet function test also showed elevated platelet activation time.

\section{Treatment}

In a case of AFX, pharmacologic or surgical intervention, or a combination or both, may be indicated. The findings of the vascular study prompted vascular surgical consultation. Because of the aortic arch anomaly, diminutive size of the left carotid system, and extensive tortuosity of the left common carotid artery, neither endovascular repair nor open surgical repair of the ulcerated, stenotic carotid origin was feasible. The twisted carotid vessel eliminated potential endovascular 
repair because the plaque could not be approached with this method. This demonstrates that the location of a plaque and the vascular anatomy are important determining factors of whether surgical intervention is appropriate. In addition, the smaller size of the entire left carotid system indicated that there was a limited risk of serious cerebral or ocular embolic events in the future, including future episodes of AFX, a TIA, or a stroke. Open surgery involving a subclavian-carotid bypass was entertained, but decided against because the patient remained asymptomatic without any recurrences. The patient was placed on an increased daily aspirin dosage of $162 \mathrm{mg}$, Lipitor $40 \mathrm{mg}$ daily, and will be monitored closely with ultrasound to attempt to prevent further embolic events. The patient has shown improvement in low-density lipoprotein and triglyceride levels to a normal range and has not had any recurrences of AFX or other cerebrovascular events since her initial visit.

\section{Discussion}

AFX has multiple etiologies, all of which result in transient retinal ischemia. Ophthalmic findings suggesting retinal ischemia or retinal artery findings of Hollenhorst plaques are of diagnostic importance, but may be absent depending on the timing of examination. In this case, no Hollenhorst plaque was seen, and the cause of the event was an embolus from an atherosclerotic plaque at the origin of the common carotid artery. AFX associated with severe atherosclerotic carotid stenosis, as in the present case, typically has a rapid onset within seconds and lasts between 1 and 10 minutes. ${ }^{2}$ The unique diagnosis of this patient results from two factors. First, this patient displayed a previously undiagnosed congenital defect with a right-sided aorta. This abnormality alone does not normally cause any problems. The second abnormality was a common origin of the left common carotid and left subclavian arteries with a tortuous common carotid artery. The origin of the left common carotid artery was stenotic, due to the formation of an atherosclerotic plaque in an abnormal location. The tortuosity of the vessel may have contributed to the formation of the plaque at this location by increasing turbulent blood flow at that region of the artery, causing endothelial damage and increasing the risk of an atherosclerotic plaque.

The primary concern over this or any other event suggesting AFX is the potential for atheroembolization from an ulcerated or unstable arterial plaque. The most common source of an atherosclerotic embolus is from the carotid bifurcation. Among patients who experienced AFX or a hemispheric TIA, $88 \%$ had a plaque identified by angiography at the carotid bifurcation, and $81 \%$ of patients had a plaque resulting in stenosis or occlusion. ${ }^{3}$ The morphology of the plaque is important to consider when assessing the risk of future embolic events.

Moore and $\mathrm{Hall}^{4}$ demonstrated the relationship between atheroembolization of the carotid artery and TIAs, and the same relationship has been established with AFX. Atherosclerotic emboli are associated with an increased risk of recurrent cerebrovascular events even when no other risk factors for stroke are present. ${ }^{5}$ This demonstrates the very important principle that AFX, along with a TIA, is a warning sign for future retinal or cerebral infarction.

AFX and TIAs present very differently but offer the same potential progression to catastrophic ischemic injury. After an episode of AFX, repeated episodes of embolization can lead to retinal artery occlusion, causing a $1 \%$ risk per year of permanent monocular blindness. ${ }^{5}$ Future episodes are also associated with cerebral arterial embolization with TIA or stroke. Large ulcerative lesions in the carotid system without any intervention present an increased risk of a stroke compared to smaller benign lesions. ${ }^{6}$ After an episode of AFX without any intervention, the risk of stroke within 2 weeks is $18.6 \%$ and within 90 days is $33 \%$. $^{7}$ When carotid stenosis is at least $70 \%$, the risk of stroke after AFX within a 2-year period is $16.6 \%{ }^{8}$

Of all parameters discussed, a careful and detailed history suggesting AFX is the most important, regardless of whether the diagnosis is verified by ophthalmic findings. Because of these findings, we strongly recommend formal vascular imaging with CT angiography of chest, neck, and head as an initial examination to be followed by vascular surgical consultation. Endarterectomy has been proven to effectively limit future embolic events and restore blood flow to the affected areas. ${ }^{9-11}$ This case shows that successful identification and treatment of this disease is of paramount importance and can prevent future damage to visual and cerebral function, even when a rare anomaly such as a right-sided aortic arch is identified in the patient.

\section{Disclosure}

The authors report no conflicts of interest in this work.

\section{References}

1. Eisenberg RL, Nemzek WR, Moore WS, Mani RL. Relationship of transient ischemic attacks and angiographically demonstrable lesions of carotid artery. Stroke. 1977;8(4):483-486.

2. Donders RC; Dutch TMB Study Group. Clinical features of transient monocular blindness and the likelihood of atherosclerotic lesions of the internal carotid artery. $J$ Neurol Neurosurg Psychiatry. 2001;71(2):247-249. 
3. Kline B. The natural history of patients with amaurosis fugax. Ophthalomol Clin NAm. 1996;9:351-357.

4. Moore WS, Hall AD. Importance of emboli from carotid bifurcation in pathogenesis of cerebral ischemic attacks. Arch Surg. 1970;101(6): 708-711.

5. Altaf N, Kandiyil N, Hosseini A, Mehta R, MacSweeney S, Auer D. Risk factors associated with cerebrovascular recurrence in symptomatic carotid disease: a comparative study of carotid plaque morphology, microemboli assessment and the european carotid surgery trial risk model. J Am Heart Assoc. 2014;3(3):e000173.

6. Moore WS, Boren C, Malone JM, et al. Natural history of nonstenotic, asymptomatic ulcerative lesions of the carotid artery. Arch Surg. 1978;113(11):1352-1359.

7. Johansson EP, Arnerlov C, Wester P. Risk of recurrent stroke before carotid endarterectomy: the ANSYSCAP study. Int J Stroke. 2013;8(4):220-227.
8. Benavente OR, Streifler JY, Harbison JW, Eliasszaw M, Hashinski VC, Barnett HJ. Differences between retinal TIA and hemispheric TIA of carotid stenosis origin: observations from NASCET. Neurology. 1992;42(Suppl 3):341.

9. Clark OH, Moore WS, Hall AD. Radiographically occluded, anatomically patent carotid arteries. Arch Surg. 1971;102(6):604-606.

10. Ben Ahmed S, Benezit M, Hazart J, Brouat A, Daniel G, Rosset E. Outcomes of the endovascular treatment for the supra-aortic trunks occlusive disease: a 14-year monocentric experience. Ann Vasc Surg. Epub March 7, 2016.

11. van de Weijer MA, Vonken EJ, de Vries JP, Moll FL, Vos JA, de Borst GJ. Technical and clinical success and long-term durability of endovascular treatment for atherosclerotic aortic arch branch origin obstruction: evaluation of 144 procedures. Eur J Vasc Endovasc Surg. 2015;50(1): 13-20.

\section{Publish your work in this journal}

The International Medical Case Reports Journal is an international, peer-reviewed open-access journal publishing original case reports from all medical specialties. Previously unpublished medical posters are also accepted relating to any area of clinical or preclinical science. Submissions should not normally exceed 2,000 words or
4 published pages including figures, diagrams and references. The manuscript management system is completely online and includes a very quick and fair peer-review system, which is all easy to use. Visit $\mathrm{http}: / /$ www.dovepress.com/testimonials.php to read real quotes from published authors.

Submit your manuscript here: https://www.dovepress.com/international-medical-case-reports-journal-journal 